\title{
STANDAR KOREKSI GEOMETRIK CITRA SATELIT RESOLUSI MENENGAH DAN MANFAAT BAGI PENGGUNA
}

\author{
Standards of Geometric Correction of Satellite Images Medium Resolution and \\ Benefits for Users
}

\author{
Reza Lukiawan, Endi Hari Purwanto dan Meilinda Ayundyahrini \\ Pusat Penelitian dan Pengembangan Standardisasi, Badan Standardisasi Nasional \\ Gedung I BPPT Lantai 12, Jalan M.H. Thamrin No. 8, Jakarta, Indonesia \\ e-mail: lukiawan@bsn.go.id
}

Diterima: 3 Desember 2018, Direvisi: 22 Februari 2019, Disetujui: 27 Februari 2019

\begin{abstract}
Abstrak
Penginderaan jauh adalah ilmu dan seni untuk memperoleh informasi tentang suatu objek, daerah atau fenomena melalui analisis data yang diperoleh dengan suatu alat tanpa kontak langsung dengan objek, atau fenomena yang dikaji. Sebelum digunakan untuk data informasi, citra satelit perlu dikoreksi geometrik agar data yang dihasilkan sesuai dengan obyek yang ada di permukaan bumi. Menurut amanah Undang - Undang Nomor 21 tahun 2013 tentang Keantariksaan bahwa perlu adanya metode dan kualitas pengolahan data penginderaan jauh yang meliputi koreksi geometrik dan radiometrik untuk mengolah data primer menjadi data proses. Penelitian ini bertujuan untuk menganalisis pentingnya standar koreksi geometrik citra satelit khususnya resolusi menengah serta untuk mengetahui manfaat data penginderaan jauh bagi stakeholders pengguna. Metode yang digunakan ialah deskriptif kuantitatif dengan objek penelitian ini yaitu responden pengguna dan pengolah data citra satelit penginderaan jauh. Hasil menunjukkan bahwa responden menganggap penting adanya standar koreksi geometrik, mayoritas responden juga menganggap bahwa data penginderaan jauh bermanfaat bagi perencanaan dan pembangunan wilayah serta pemantauan sumber daya alam dan lingkungan. Manfaat penelitian ini adalah dengan diterapkannya standar proses koreksi geometrik diharapkan dapat mengatasi masalah distorsi data penginderaan jauh dan menghasilkan ketelitian, kualitas geometrik yang sesuai standar sehingga menghasilkan data penginderaan jauh yang akurat sesuai dengan obyek yang ada di bumi yang pada akhirnya berguna bagi pengguna khususnya untuk pemantauan sumber daya alam dan pengembangan wilayah. Sehingga diharapkan nantinya standar yang ditetapkan menjadi acuan bagi seluruh stakeholders yang melakukan pengolahan data penginderaan jauh.
\end{abstract}

Kata kunci: koreksi geometrik, citra resolusi menengah, manfaat data penginderaan jauh

\begin{abstract}
Remote Sensing is science and art to obtain information about an object, region or phenomenon through analysis of data obtained with a tool without direct contact with the object, or the phenomenon under study. Before being used for information data, satellite images need to be corrected geometrically so that the data produced is in accordance with objects that are on the surface of the earth. According to the mandate of Law Number 21 of 2013 concerning Space, there is a need for methods and quality of remote sensing data processing that includes geometric and radiometric corrections to process primary data into process data. This study aims to analyze the importance of satellite image geometric correction standards, especially medium resolution and to determine the benefits of remote sensing data for user stakeholders. The method used is descriptive quantitative with the object of this research is the respondent user and processing of remote sensing satellite image data The results show that respondents consider the importance of geometric correction standards, the majority of respondents also consider that remote sensing data is useful for regional planning and development and natural resource and environmental monitoring. The benefit of this research is that the implementation of standard geometric correction process is expected to overcome distortion of remote sensing data problems and produce accuracy, geometric quality that conforms to standards so as to produce accurate remote sensing data in accordance with objects on earth which are ultimately useful for users especially for monitoring natural resources and regional development. So that it is expected that later the standards set will become a reference for all stakeholders who are processing remote sensing data.
\end{abstract}

Keywords: geometric correction, medium resolution imagery, benefits of remote sensing data 


\section{PENDAHULUAN}

Penginderaan jauh didefinisikan sebagai suatu seni dalam mengolah dan menafsirkan citra untuk mendapatkan suatu informasi. Teknologi penginderaan jauh adalah suatu kegiatan pengamatan obyek atau suatu daerah tanpa melalui kontak langsung dengan obyek tersebut (Lillesand, 1994). Data mentah citra satelit memiliki berbagai macam resolusi seperti rendah, menengah, tinggi dan sangat tinggi.

Pemanfaatan citra dengan resolusi tinggi dan turunannya adalah untuk memperbarui peta skala besar yang berguna untuk memantau perkembangan bangunan di suatu wilayah. Akan tetapi pemanfaatan teknologi ini untuk updating peta skala besar mempunyai beberapa kendala, misalnya perekaman data oleh sensor satelit yang tidak dapat digunakan secara langsung karena masih terdapat beberapa kesalahan geometrik yang harus dieliminir (A'yun, 2013). Untuk mengeleminasi berbagai kesalahan geometrik, maka dilakukan koreksi geometrik.

Menurut Lembaga Penerbangan dan Antariksa Nasional (LAPAN), citra satelit yang direkam melalui sensor satelit pada dasarnya masih mempunyai kesalahan yang diakibatkan oleh kesalahan sistematik dan non-sistematik. Kesalahan sistematik disebabkan antara lain oleh faktor kelengkungan permukaan bumi, sedangkan kesalahan non-sistematis diakibatkan oleh perbedaan tinggi pada objek di permukaan bumi. Proses untuk koreksi kesalahan sistematis secara langsung memalui proses koreksi geometrik dengan menggunakan parameter satelit saat perekaman. Kesalahan non-sistematis bisa dieliminasi dengan melakukan koreksi orthorektifikasi. Orthorektifikasi adalah sistem koreksi geometrik untuk eliminasi kesalahan akibat perbedaan tinggi permukaan bumi serta proyeksi akuisisi citra yang umumnya tidak orthogonal.

Citra tegak merupakan citra yang telah dikoreksi segala kesalahan geometriknya akibat dari mekanisme perekaman citra. Kesalahan geometrik citra bisa berasal dari kesalahan internal satelit, sensor (sensor miring/ off-nadir) ataupun kesalahan eksternal. Perekaman off-nadir dan permukaan bumi yang ketinggiannya tidak sama menyebabkan adanya kesalahan pergeseran relief. Pergeseran relief merupakan ketidaktepatan posisi suatu objek pada citra yang disebabkan oleh beda tinggi terhadap bidang referensi (Harintaka, 2003).

Menurut amanah Undang - Undang Nomor 21 tahun 2013 tentang Keantariksaan bahwa perlu adanya metode dan kualitas pengolahan data penginderaan jauh yang meliputi koreksi geometrik dan radiometrik untuk mengolah data primer menjadi data proses. Hal ini dipertegas dalam Pasal 19 ayat 2 bahwa pengolahan data penginderaan jauh wajib dilakukan dengan mengacu pada metode dan kualitas pengolahan data penginderaan jauh yang ditetapkan oleh lembaga. Berdasarkan uraian tersebut, tujuan dari penelitian ini adalah untuk menganalisis pentingnya standar koreksi geometrik citra satelit khususnya resolusi menengah yang memiliki resolusi spasial 4-30 m perlu koreksi dasar citra agar memiliki sifatsifat peta dalam bentuk, skala sesuai dengan obyek di permukaan bumi serta untuk mengetahui manfaat data penginderaan jauh bagi stakeholders pengguna, karena hipotesisnya ialah kebutuhan data citra satelit penginderaan jauh saat ini sangat dibutuhkan untuk perencanaan dan pembangunan wilayah.

\section{TINJAUAN PUSTAKA}

\subsection{Definisi Penginderaaan Jauh}

Penginderaan jauh (atau disingkat inderaja) adalah pengukuran atau akuisisi data dari sebuah objek atau fenomena oleh sebuah alat yang tidak secara fisik melakukan kontak dengan objek tersebut atau pengukuran atau akuisisi data dari sebuah objek atau fenomena oleh sebuah alat dari jarak jauh, (misalnya dari pesawat, pesawat luar angkasa, satelit, kapal atau alat lain). Penginderaan jauh adalah ilmu dan seni untuk memperoleh informasi tentang suatu objek, daerah atau fenomena melalui analisis data yang diperoleh dengan suatu alat tanpa kontak langsung dengan objek, atau fenomena yang dikaji (Lillesand, 2004). Teknologi inderaja, dalam hal ini citra satelit beresolusi tinggi, dipandang sebagai metode yang tepat untuk memperoleh data tutupan/penggunaan lahan.

Teknologi ini mampu meliput wilayah yang luas, mutakhir, tersedia dengan berbagai tingkat kerincian sesuai keperluan, serta semakin mudah dan murah dalam memperolehnya. Pembuatan peta tutupan lahan secara manual dengan pemetaan langsung di lapangan akan sangat mahal biayanya bila dibandingkan dengan interpretasi foto udara (Amelia, 2015).

\subsection{Koreksi Geometrik}

Geometrik merupakan posisi geografis yang berhubungan dengan distribusi keruangan (spatial distribution). Geometrik memuat informasi data yang mengacu bumi (geo-referenced data), baik posisi (sistem koordinat lintang dan bujur) maupun informasi yang terkandung didalamnya. Menurut Mather (1987), koreksi geometrik adalah transformasi citra hasil penginderaan jauh sehingga citra tersebut mempunyai sifat-sifat peta dalam bentuk, skala dan proyeksi. Transformasi geometrik yang paling mendasar adalah 
penempatan kembali posisi pixel sedemikian rupa, sehingga pada citra digital yang tertransformasi dapat dilihat gambaran objek di permukaan bumi yang terekam sensor. Pengubahan bentuk kerangka liputan dari bujur sangkar menjadi jajaran genjang merupakan hasil transformasi ini. Tahap ini diterapkan pada citra digital mentah (langsung hasil perekaman satelit), dan merupakan koreksi kesalahan geometrik sistematik.

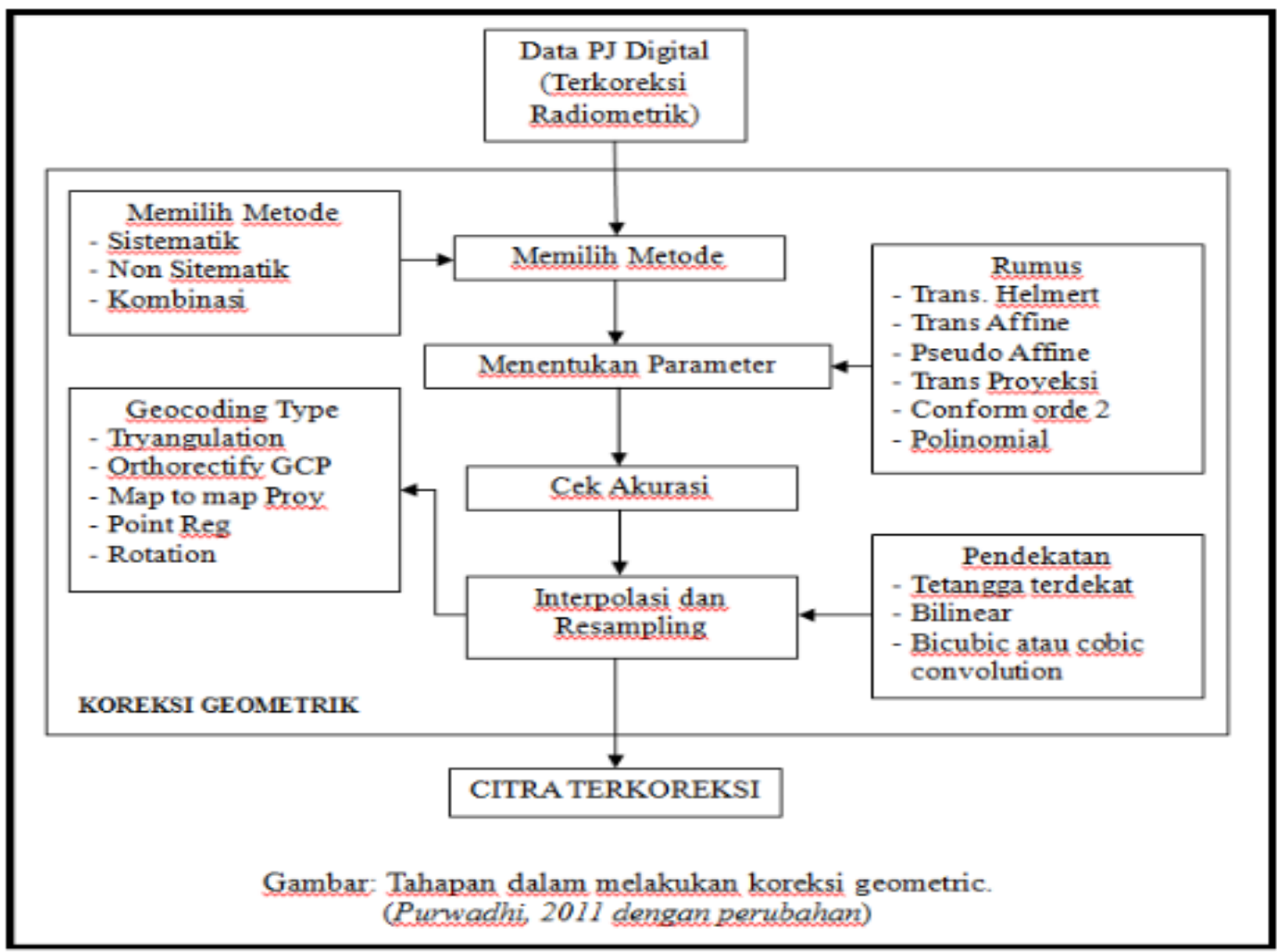

Gambar 1 Tahapan koreksi geometrik.

\subsection{Koreksi radiometrik}

Koreksi radiometrik ditujukan untuk memperbaiki nilai piksel supaya sesuai dengan yang seharusnya yang biasanya mempertimbangkan faktor gangguan atmosfer sebagai sumber kesalahan utama. Efek atmosfer menyebabkan nilai pantulan objek dipermukaan bumi yang terekam oleh sensor menjadi bukan merupakan nilai aslinya, tetapi menjadi lebih besar oleh karena adanya hamburan atau lebih kecil karena proses serapan. Metode-metode yang sering digunakan untuk menghilangkan efek atmosfer antara lain metode pergeseran histogram (histogram adjustment), metode regresi dan metode kalibrasi bayangan (Danoedoro, 1996). Koreksi radiometrik adalah koreksi dasar citra yang dilakukan untuk menghilangkan noise yang terdapat pada citra sebagai akibat dari adanya distorsi oleh posisi cahaya matahari, dan salah satu contoh citra satelit yang memerlukan proses ini adalah citra Satelit Landsat (Rahayu \& Candra, 2014).

\subsection{Manfaat Data Penginderaan Jauh}

Penginderaan jauh adalah salah satu metode yang sedang berkembang dan banyak digunakan juga memiliki peran penting dalam berbagai kegiatan. Beberapa peranan penginderaan jauh adalah sebagai berikut:

1. Aplikasi penginderaan jauh dalam mengidentifikasi persebaran mineral bumi. Pembicaraan mengenai penginderaan jauh tidak akan jauh dari citra satelit, dalam kenyataannya ada begitu banyak jenis citra satelit yang digunakan. Dengan melihat dari spesifikasi citra satelit yang ada dan fungsi dari tiap bandnya, citra tersebut dapat digunakan untuk menidentifikasi persebaran mineral. Menurut Ambodo (2008) dengan menggunakan citra Landsat 5 TM dan metode interpretasi citra dapat mengidentifikasi persebaran batubara didasarkan pada topografi dan struktur geologinya.

2. Aplikasi penginderaan jauh untuk sebaran dan luas hutan mangrove di wilayah pesisir. Sebaran dan luas hutan mangrove dapat 
dilakukan dengan menggunakan citra Landsat 7 ETM dan menggunakan software pendukungnya. Metode yang digunakan dalam pengaplikasian penginderaan jauh ini adalah dengan menggunakan klasifikasi multispekral terkontrol dan algoritma jaringan saraf tiruan yang dilakukan dengan perbandingan komposit warna yang muncul melalui kombinasi band-bandnya dan pengecekan di lapangan (Taringan, 2008).

3. Studi perubahan tutupan lahan dengan citra Landsat menggunakan geographic resources analyis support system (grass). Dalam pembuatan peta tutupan lahan, dapat dilakukan dengan memanfaatkan teknologi penginderaan jauh, misalnya dengan menganalisa citra satelit Landsat. Dalam melakukan analisa tersebut, menggunakan perangkat lunak pengolah citra open source (bebas digunakan namun tetap dengan legalitas dari pembuatnya) yaitu Geographic Resources Analysis Support System (GRASS). Pengolahan citra Landsat pada GRASS melalui tahap import data, penggabungan band (red, green dan blue), konversi data vektor menjadi data raster, rektifikasi (koreksi geometrik), digitasi dan klasifikasi dengan metode klasifikasi terselia. Analisa perubahan luas tutupan lahan dibagi menjadi lima kelas yakni permukiman, ladang/kebun, lahan kosong, lahan basah dan rawa/tambak. Dengan membandingkan hasil pengolahan citra satelit Landsat maka diketahui besarnya perubahan tutupan lahannya (Winardi, 2010).

4. Pola sebaran sedimen tersuspensi melalui pendekatan penginderaan jauh. Distribusi sedimen tersuspensi (TSS) di wilayah perairan untuk dievaluasi khususnya daerah yang akan dikembangkan infrastruktur di wilayah pesisir. Evaluasi pola distribusi sedimen tersuspensi telah dilakukan dengan pengukuran lapangan dan penginderaan jauh. Kajian citra penginderaan jauh ini menggunakan data multi temporal yang mempunyai karakteristik spectral yang hampir sama untuk itu citra Landsat MSS TM dan ETM digunakan dan diolah menngunakan software Er Mapper untuk mendapatkan nilai konsentrasi TSS. Data citra Landsat Ortho digunakan sebagai acuan dalam georeferensi atau penyamaan sistem koordinat citra-citra Landsat yang digunakan dan dalam menganalisis konsentrasi TSS (Susiati, 2010).

5. Aplikasi penginderaan jauh untuk mendeteksi kerapatan vegetasi. Vegetasi merupakan keseluruhan tumbuhan dari suatu area yang berfungsi sebagai penutup lahan. Tumbuhan tersebut bisa bersifat alami maupun hasil budidaya, homogen maupun heterogen. Persebaran vegetasi dalam suatu area dapat dipengaruhi oleh kondisi topografi. Kondisi topografi yang bervariasi, yaitu daerah pegunungan berbukit, daerah dataran rendah, dan daerah pantai, variasi ini berpengaruh terhadap persebaran vegetasi yang ada di wilayah tersebut. Salah satu metode yang dapat digunakan untuk mengamati perubahan vegetasi adalah dengan menggunakan teknologi penginderaan jauh dengan citra satelit Landsat 7 ETM+ dan citra satelit SPOT4. Hasil dari proses pengolahan citra adalah informasi mengenai indeks vegetasi citra dan tutupan lahan daerah penelitian. Hubungan tersebut diperoleh melalui uji korelasi. Hasil uji korelasi antara indeks vegetasi NDVI Landsat, EVI Landsat, NDVI SPOT 4 (Maryantika, 2009).

\section{METODE PENELITIAN}

Pendekatan penelitian ini menggunakan analisis deskriptif kuantitatif. Sudjana (2001) mendefinisikan penelitian deskriptif adalah penelitian yang berusaha mendeskripsikan suatu gejala, peristiwa, kejadian yang terjadi pada saat sekarang. Sebagaimana yang dikemukakan oleh Sudjana (2001) bahwa metode penelitian deskriptif dengan pendekatan secara kuantitatif digunakan apabila bertujuan untuk mendeskripsikan atau menjelaskan peristiwa atau suatu kejadian yang terjadi pada saat sekarang dalam bentuk angka-angka yang bermakna.

Objek penelitian ini yaitu responden pengguna dan pengolah data citra satelit penginderaan jauh, seperti Bappeda, Dinas Pekerjaan Umum dan Penataan Ruang, perusahaan konsultan, para akademisi. Adapun lokus penelitian yang dilakukan kunjungan survei lapangan meliputi Bengkulu, Kendari, Pontianak, Semarang, Palangkaraya, Makassar, Jambi, Bogor dan Gorontalo. Jumlah responden yang terkumpul sebanyak 44 responden.

Pengumpulan data primer dilakukan dengan survei lapangan/wawancara langsung dan menggunakan alat bantu berupa kuesioner untuk mendapatkan jawaban persepsi responden tentang pentingnya standar koreksi geometrik citra satelit khususnya resolusi menengah serta untuk mengetahui manfaat data penginderaan jauh bagi stakeholders pengguna. Kuesioner penelitian berisikan pertanyaan yang terkait dengan pentingnya standar koreksi geometrik citra satelit khususnya resolusi menengah serta untuk mengetahui manfaat data penginderaan jauh bagi stakeholders pengguna. 


\section{HASIL DAN PEMBAHASAN}

\subsection{Analisis Pentingnya Standar Koreksi Geometrik}

Hal penting dalam analisis citra digital adalah unsur resolusi. Resolusi tersebut diantaranya resolusi spasial, resolusi spektral, resolusi radiometrik, dan resolusi temporal. Resolusi spasial merupakan ukuran terkecil obyek di lapangan yang dapat direkam pada data digital maupun pada citra. Pada data digital resolusi dilapangan dinyatakan dengan pixel. Semakin kecil ukuran terkecil yang dapat direkam oleh suatu sistem sensor, berarti sensor itu semakin baik karena dapat menyajikan data dan informasi yang semakin rinci. Resolusi spasial yang baik dikatakan resolusi tinggi atau halus, sedang yang kurang baik berupa resolusi kasar atau rendah (Suwargana, 2013). Karakteristik dan tipe data penginderaan jauh beserta resolusi spasialnya seperti pada Tabel 1.

Tabel 1 Tipe Data penginderaan jauh.

\begin{tabular}{|c|c|c|}
\hline Type & Sensor/product & spatial resolution \\
\hline \multirow{5}{*}{$\begin{array}{c}\text { Coarse } \\
\text { resolution } \\
\text { satellite } \\
\text { sensor } \\
(100 \text { to } 1 \\
\mathrm{km})\end{array}$} & NOAA-TIROS & $1,1 \mathrm{~km}$ \\
\hline & $\begin{array}{l}\text { SPOT } \\
\text { VEGETATION }\end{array}$ & $1,15 \mathrm{~km}$ \\
\hline & ADEOS II & $\begin{array}{l}7 \mathrm{~km} \times 6 \mathrm{~km}, 250 \mathrm{~m}- \\
250 \mathrm{~km}\end{array}$ \\
\hline & $\begin{array}{l}\text { EOS AM and } \\
\text { PM (MODIS) }\end{array}$ & $250-1000 \mathrm{~m}, 275 \mathrm{~m}$ \\
\hline & Envisat & $\begin{array}{l}350-1200 \mathrm{~m}, 150- \\
1000 \mathrm{~m}\end{array}$ \\
\hline \multirow{7}{*}{$\begin{array}{c}\text { Moderate } \\
\text { resolution } \\
\text { satellite } \\
\text { sensor } \\
(10-100 \\
\mathrm{m})\end{array}$} & SPOT & $20 \mathrm{~m} ; 10 \mathrm{~m}$ \\
\hline & ERS & $30 \mathrm{~m}$ \\
\hline & Radarsat & $10-100 m$ \\
\hline & Landsat & $83,30 \mathrm{~m}$ \\
\hline & Landsat & $15-100 m$ \\
\hline & EOS & $15-90 m$ \\
\hline & JERS & $18 \mathrm{~m}, 18 \mathrm{~m} \times 24$ \\
\hline \multirow{3}{*}{$\begin{array}{c}\text { High } \\
\text { resolution } \\
\text { satellite } \\
\text { sensor } \\
(<10 \mathrm{~m})\end{array}$} & IKONOS & $\begin{array}{l}1 \text { m panchromatic; } \\
4 \mathrm{~m} \text { multispectral }\end{array}$ \\
\hline & Quickbird & $\begin{array}{l}0,61 \mathrm{~m} \\
\text { panchromatic; } 2.44 \\
\mathrm{~m} \text { multispectral }\end{array}$ \\
\hline & Geo eye & $\begin{array}{l}34 \mathrm{~cm} \text { panchromatic; } \\
1,36 \mathrm{~m} \text { multispectral }\end{array}$ \\
\hline
\end{tabular}

Sumber: Loveland dan Defries (2013).

Pada penelitian ini didasarkan juga pada usulan parameter untuk standar koreksi geometrik data satelit resolusi menengah yang telah diusulkan LAPAN dengan data resolusi spasial lebih besar dari 4 (empat) meter dan kurang atau sama dengan 30 meter. Apabila mengacu pada nilai resolusi spasial dalam draft standar tersebut, maka terdapat beberapa sensor satelit yang sesuai seperti SPOT,
Landsat, Radarsat. Menurut Suwargana (2013), Beberapa contoh satelit bumi yang mempunyai resolusi spasial adalah:

a. Landsat : 15 meter pada mode pankromatik dan 30 meter pada mode multispektral

b. Spot : 10 meter pada mode pankromatik dan 20 meter pada mode multispektral

c. Ikonos : 1 meter pada mode pankromatik dan 4 meter pada mode multispektral.

Selain itu, usulan draft standar ini juga perlu diperoleh respon/persepsi dari responden. Kuesioner penelitian sebagai tools untuk menggali pentingnya standar koreksi geometrik dijabarkan dengan pertanyaanpertanyaan sebagai berikut:

1. Penginderaan jauh memiliki peran yang sangat penting bagi pembangunan bangsa dan data yang dihasilkan dari penginderaan jauh bisa dimanfaatkan untuk berbagai kepentingan (Q1)

2. Telah dikembangkan Bank Data Penginderaan Jauh Nasional dan Sistem Pemantauan Bumi Nasional. Bank data ini bisa dimanfaatkan oleh kementerian/lembaga dan pemerintah daerah secara gratis $(\mathrm{Q} 2)$

3. Data penginderaan jauh yang berupa data primer (data mentah dari satelit yang belum diolah) diperlukan suatu cara atau metode yang terstandar untuk mengolahnya sehingga dapat dimanfaatkan oleh pihakpihak yang memerlukan dan tidak menimbulkan keanekaragaman perbedaan hasil (Q3)

4. Hasil pengolahan data indera jauh harus dapat dipertanggungjawabkan secara ilmiah dan mempunyai liabilitas yang tinggi (berkekuatan hukum), sehingga sangat penting untuk distandardisasi metode pengolahan data indera jauh (Q4)

5. Usulan standar tentang koreksi geometrik data optik satelit penginderaan jauh resolusi menengah untuk dijadikan $\mathrm{SNI}$ (Q5)

Adapun hasil dari jawaban responden, terdapat 4 (empat) pertanyaan yaitu Q1,Q3,Q4 dan Q5 yang keseluruhan responden (100\%) menjawab setuju/YA. Sedangkan pada pertanyaan Q2, 93\% responden menjawab setuju sementara $7 \%$ menjawab tidak setuju dengan alasan bahwa terlihat pada Gambar 2.

Adanya suatu acuan standar untuk pengolahan data mentah citra satelit menjadi data proses dalam tahapan koreksi geometrik perlu diwujudkan, karena hal ini bertujuan untuk menghasilkan kualitas data citra satelit tersebut. Koreksi geometric dilakukan karena 
terjadi distorsi geometric antara citra hasil penginderaan dan objeknya. Distorsi geometric adalah ketidaksempurnaan geometri citra yang terekam pada saat pencitraan, hal ini menyebabkan ukuran, posisi, dan bentuk citra menjadi tidak sesuai dengan kondisi sebenarnya. Distorsi geometric ini harus dikoreksi dahulu sebelum citra digunakan (Nurwauziyah, 2016).

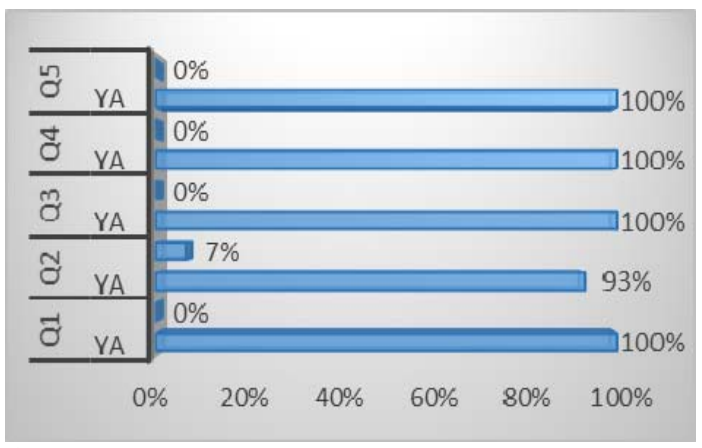

Gambar 2 Persepsi dan pemahaman responden terhadap usulan standar koreksi geometrik.

\subsection{Analisis manfaat data penginderaan jauh bagi pengguna}

Data citra satelit penginderaan jauh dalam tren perkembangan saat ini mulai banyak dimanfaatkan. Sebagai contoh, penelitian oleh Auliya (2017) yang melakukan penentuan garis pantai pada data citra satelit Landsat dan UAV kemudian dibandingkan efektivitas dari keduanya dilihat dari ketelitian horisontal dalam penyajian skala di peta. Kemudian penelitian yang bertujuan untuk mengkaji kemampuan citra ALOS AVNIR-2 untuk identifikasi bentuk lahan, memetakan bentuk lahan semi detil skala 1:50.000 berdasarkan pendekatan analitik dengan bantuan Sistem Informasi Geografis (SIG), dan mengevaluasi citra ALOS AVNIR-2 dalam pemetaan bentuk lahan (landform) (Tufaila, 2012).

Tabel 2 Alasan manfaat data penginderaan jauh.

\begin{tabular}{|c|c|c|}
\hline No. & Kelompok Instansi & Alasan Manfaat \\
\hline 1 & Bappeda & $\begin{array}{l}\checkmark \text { Memberikan informasi penginderaan jauh dalam mendukung } \\
\text { perumusan standar untuk kepentingan dalam rangka } \\
\text { perumusan standar } \\
\checkmark \text { Citra memudahkan menganalisa wilayah untuk mendapatkan } \\
\text { rona awal } \\
\checkmark \text { Sebelum mengeluarkan kebijakan kita mengetahui } \\
\text { karakteristik wilayah tersebut }\end{array}$ \\
\hline 2 & $\begin{array}{l}\text { Dinas Pekerjaan Umum dan } \\
\text { Penataan Ruang }\end{array}$ & 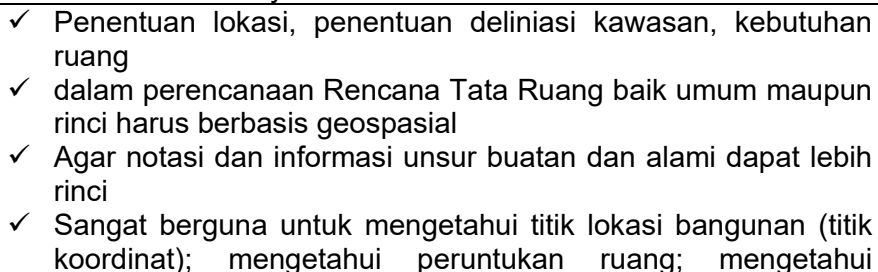 \\
\hline
\end{tabular}

Penelitian sejenis yang dilakukan oleh Kushardono (2016) mengelompokkan pemanfaatan informasi data penginderaan jauh kebutuhan pengguna menjadi 3 kelompok yaitu bidang sumberdaya wilayah darat, bidang sumberdaya wilayah pesisir dan laut, serta bidang lingkungan dan mitigasi bencana.

Pada penelitian ini juga ingin mengetahui seberapa besar manfaat data penginderaan jauh bagi stakeholders pengguna dan pengolah data. Berdasarkan jawaban dari responden atas pertanyaan yang ada dalam kuesioner, Seluruh responden menjawab setuju (100\%) bahwa data penginderaan jauh memberikan informasi tentang objek, daerah, atau gejala di darat, laut, dan atmosfer serta antariksa yang diindera melalui satelit dan/atau wahana lain. Data ini dapat memberikan manfaat bagi perencanaan dan pembangunan wilayah serta pemantauan sumberdaya alam . Hal ini terlihat pada Gambar 3.

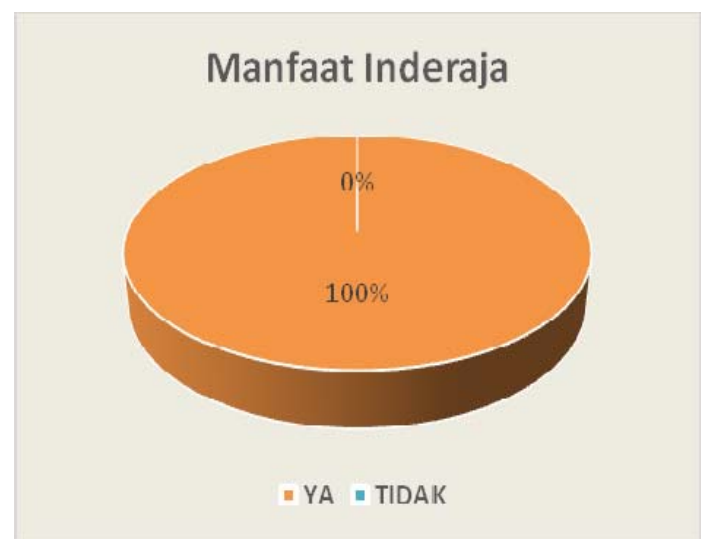

Gambar 3 Persepsi responden mengenai manfaat data penginderaan jauh.

Beberapa alasan responden mengenai manfaat data penginderaan jauh dan dikelompokkan berdasarkan instansinya seperti terlihat pada Tabel 2. 


\begin{tabular}{|c|c|c|}
\hline No. & Kelompok Instansi & Alasan Manfaat \\
\hline & & $\begin{array}{l}\text { panjang dan luasan dari kawasan } \\
\checkmark \text { Dengan adanya citra satelit, dapat diketahui kontur wilayah } \\
\text { yaitu dengan adanya DEM } \\
\checkmark \text { Data penginderaan jauh sebagai data pendukung dalam } \\
\text { pengambilan keputusan dalam perencanaan } \\
\checkmark \text { Dengan data penginderaan jarak jauh, SKPD yang } \\
\text { membidangi perencanaan dan pembangunan wilayah dapat } \\
\text { dengan mudah memantau perubahan maupun pelanggaran } \\
\text { pemanfaatan ruang }\end{array}$ \\
\hline & Perguruan Tinggi & $\begin{array}{l}\checkmark \text { Sebagai bagian dari data primer } \\
\checkmark \text { Data penginderaan jauh lebih fleksibel aplikasinya. Mudah } \\
\text { dalam proses permodelan dan modifikasi data dan dapat } \\
\text { diperbaharui secara berkala } \\
\checkmark \quad \begin{array}{l}\text { Data dasar merupakan hal dasar dalam perencanaan, dimana } \\
\text { data dasar harus memiliki tingkat kevalidannya harus benar }\end{array} \\
\checkmark \quad \begin{array}{l}\text { Kemampuan monitoring dari wahana inderaja dan didukung } \\
\text { oleh ragam resolusi spasial mampu menyediakan variasi detail } \\
\text { informasi pada setiap objek di permukaan bumi }\end{array} \\
\checkmark \quad \begin{array}{l}\text { Dengan penginderaan jauh kita akan menjadi lebih mudah } \\
\text { untuk melihat perubahan tutupan lahan dari waktu ke waktu }\end{array}\end{array}$ \\
\hline & Perusahaan swasta & $\begin{array}{l}\checkmark \text { Dengan adanya data penginderaan jauh sangat membantu } \\
\text { bagi perencanaan dan pembangunan wilayah } \\
\checkmark \text { Perlu karena dapat memberikan pengembangan metode yang } \\
\text { tepat guna untuk para peneliti maupun swasta untuk } \\
\text { keperluan riset atau proyek pekerjaan }\end{array}$ \\
\hline
\end{tabular}

\subsection{Kendala Pemanfaatan Penginderaan Jauh}

Data penginderaan jauh sudah banyak dibutuhkan oleh berbagai pihak baik pemerintah, swasta maupun akademisi perguruan tinggi. Apalagi saat ini program Kebijakan Satu Peta sedang dipercepat oleh pemerintah. Melalui program Percepatan Kebijakan Satu Peta (PKSP), pemerintah daerah didorong segera memperbaiki perencanaan wilayahnya dengan berdasarkan peta yang sudah terkoreksi.

Namun pada kenyataan di lapangan saat ini masih terkendala oleh beberapa hal. Berdasarkan hasil penelitian ini, dirangkum beberapa kendala yang dikategorikan dalam 4 aspek. Kendala-kendala tersebut tersaji pada Tabel 3.

Tabel 3 Kendala dan permasalahan pemanfaatan data penginderaan jauh.

\begin{tabular}{|c|c|c|}
\hline No. & Aspek & Kendala dan Permasalahan \\
\hline 1 & Akses Data Penginderaan Jauh & $\begin{array}{l}\checkmark \text { Permohonan peroleh data citra satelit penginderaan jauh ke } \\
\text { LAPAN diperlukan surat resmi dari pejabat daerah minimal } \\
\text { setingkat Sekretaris daerah. } \\
\checkmark \quad \text { Proses waktu dan birokrasi yang lama di daerah } \\
\text { menyebabkan durasi permohonan data menjadi lebih lama. } \\
\checkmark \quad \text { LAPAN telah menyediakan Bank Data Penginderaan Jauh } \\
\text { Nasional (BDPJN), tapi hal ini belum banyak diketahui } \\
\checkmark \quad \text { Masalah update tahun data tidak sesuai kebutuhan pengguna }\end{array}$ \\
\hline 2 & SDM dan kompetensi personil & $\begin{array}{l}\text { Pemerintah daerah masih minim memiliki SDM yang } \\
\text { kompeten di bidang penginderaan jauh } \\
\checkmark \quad \text { Personil yang dibutuhkan sebagai tenaga pengolah data } \\
\text { penginderaan jauh adalah yang berkualifikasi sesuai dengan } \\
\text { latar belakang pendidikan yang sesuai seperti geodesi, } \\
\text { geomatika, planologi, perencanaan wilayah } \\
\checkmark \quad \text { Tidak semua daerah menjalin kerjasama dengan akademisi } \\
\text { perguruan tinggi sebagai pihak yang kompeten }\end{array}$ \\
\hline 3 & Biaya dan Alat & $\begin{array}{l}\checkmark \quad \text { Biaya yang dianggarkan pemerintah daerah untuk pembuatan } \\
\text { peta Rencana Detail Tata Ruang (RDTR) mahal. } \\
\checkmark \quad \text { Alat yang digunakan untuk penentuan titik kontrol GCP/ICP } \\
\text { yaitu GPS geodetic harganya mahal. } \\
\checkmark \quad \text { Pemerintah daerah mengeluarkan biaya untuk hire konsultan } \\
\text { independen yang diminta untuk mengolah data mentah/primer } \\
\text { menjadi data proses agar dapat dimanfaatkan informasinya. }\end{array}$ \\
\hline
\end{tabular}




\begin{tabular}{|c|c|c|}
\hline No. & Aspek & Kendala dan Permasalahan \\
\hline & Kelembagaan & 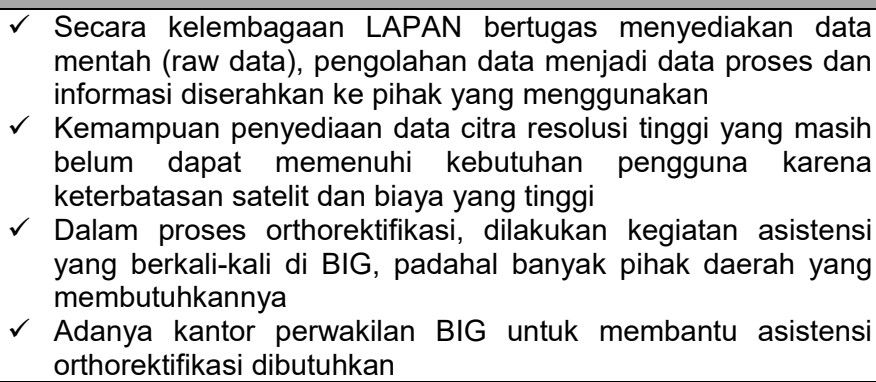 \\
\hline
\end{tabular}

Beberapa kendala dan permasalahan yang dihadapi baik oleh pemerintah daerah maupun stakeholders terkait dalam 4 aspek tersebut, dapat diminalisir dengan cara-cara seperti 1) sosialisasi dan pemanfaatan jaringan informasi data penginderaan jauh dan peta seperti peta rupa bumi, DEMNAS makin diperluas, 2) perekrutan personil di masingmasing pemerintah daerah dengan latar belakang penginderaan jauh diperbanyak, 3) penguatan kelembagaan dengan membuat kerjasama dengan perguruan tinggi yang ada di daerah, 4) prioritas penganggaran untuk pengadaan pembelian alat dan pengolahan data.

\subsection{Tanggapan terhadap draft standar koreksi geometrik}

Penelitian yang dilakukan selain survei lapangan untuk menggali jawaban responden, juga dilakukan diskusi dengan pakar informasi geospasial penginderaan jauh. Poin-poin yang menjadi masukan antara lain:

1) Secara kuantitatif koreksi geometrik dapat diekspresikan sebagai sifat yang berkaitan dengan karakter geometrik yaitu dapat diukur/diamati secara dimensional atau bersifat geometrik atau dengan kata tanya seperti berapa dan dimana, berapa berarti obyek yang ada dipermukaan bumi tersebut diamati/diukur dimensi/ukurannya dan dimana berarti apakah obyek tersebut berada dimana posisi/kedudukan/koordinatnya dibumi ini secara relatif terhadap titik atau sistem koordinat yang digunakan sebagai referensi/acuan atau harus bersifat georeference. Sehingga disini dibutuhkan analisa yang bersifat obyektif dari pengamat/pengukur dan akan lebih baik apabila pengamat/pengukur tersebut mempunyai kepakaran/kompetensi yang sesuai dengan apa yang diamati/diukur. Untuk mendapatkan hasil yang benar secara radiometrik perlu dilakukan koreksi geometrik dan pengukuran titik kontrol tanah (ground control point: GCP) dilapangan.
Koreksi geometrik dapat dilakukan di laboratorium yaitu dengan menghilangkan kesalahan yang diakibatkan oleh karakter/perilaku satelit pada orbitnya dan sifat fisik bumi, memperbaiki kesalahan geometrik dilakukan dengan cara melakukan proyeksi/transformasi setiap pixel ke sistem koordinat tertentu (contoh Universal Transverse Mercator: UTM) pada peta atau titik kontrol tanah (GCP) yang telah mempunyai koordinat geografis maupun koordinat proyeksi. Oleh karena itu, perlu diuji hasil yang diperoleh dengan melakukan transformasi atau tumpang susun (overlay) antara citra yang ada dengan dokumen yang lain (peta, foto, citra) yang telah mempunyai sistem koordinat (geografis atau proyeksi) yaitu dengan melihat nilai penyimpangannya (root mean squares $=$ RMS error), melihat ketelitian petanya (map accuracy). Sedangkan dilapangan dilakukan dengan melakukan verifikasi dengan pengukuran/pengamatan dengan menggunakan alat Global Positioning System (GPS)

2) Metode koreksi geometrik, baik antara image, image dengan peta maupun image dengan data lapangan universal.

3) Standar koreksi geometrik sangat dinamis mengikuti perkembangan teknologi oleh karena itu apabila diberlakukan sebaiknya bersifat sukarela.

4) Orthorektifikasi diperlukan untuk akurasi terkait ketinggian.

\section{KESIMPULAN}

Berdasarkan hasil penelitian bahwa proses koreksi geometrik untuk data citra satelit penginderaan jauh diperlukan suatu metode yang terstandar. Sebanyak $100 \%$ responden menyatakan setuju bahwa penginderaan jauh memiliki peran yang sangat penting bagi pembangunan bangsa dan data yang dihasilkan dari penginderaan jauh bisa dimanfaatkan untuk berbagai kepentingan, responden juga seluruhnya menyetujui bahwa 
data penginderaan jauh yang berupa data primer (data mentah dari satelit yang belum diolah) diperlukan suatu cara atau metode yang terstandar untuk mengolahnya sehingga dapat dimanfaatkan oleh pihak-pihak yang memerlukan dan tidak menimbulkan keanekaragaman perbedaan hasil, seluruh responden juga setuju hasil pengolahan data indera jauh harus dapat dipertanggungjawabkan secara ilmiah dan mempunyai liabilitas yang tinggi (berkekuatan hukum) apabila digunakan ketika terjadi masalah sengketa. Berkaitan dengan BDPJN, sebanyak $93 \%$ responden setuju sedangkan $7 \%$ menyatakan tidak setuju karena hanya dibatasi untuk kementerian/lembaga dan pemerintah daerah.

Sementara itu, penilaian responden mengenai apakah data penginderaan jauh bermanfaat, seluruh responden menyetujuinya karena memberikan informasi tentang objek, daerah, atau gejala di darat, laut, dan atmosfer serta antariksa yang diindera melalui satelit dan/atau wahana lain. Sehingga bermanfaat bagi perencanaan dan pembangunan wilayah serta pemantauan sumberdaya alam.

Kendala dan permasalahan yang dihadapi oleh responden di daerah-daerah lokus penelitian secara garis besar dikelompokkan dalam 4 aspek yaitu Akses data penginderaan jauh, SDM dan kompetensi personil, biaya dan alat serta kelembagaan. Aspel-aspek tersebut perlu diatasi oleh pemerintah apabila ingin mewujudkan percepatan Kebijakan Satu Peta. Antara lain, (1) sosialisasi dan pemanfaatan jaringan informasi data penginderaan jauh dan peta seperti peta rupa bumi, DEMNAS makin diperluas (2) perekrutan personil di masingmasing pemerintah daerah dengan latar belakang penginderaan jauh diperbanyak (3) penguatan kelembagaan dengan membuat kerjasama dengan perguruan tinggi yang ada di daerah, (4) prioritas penganggaran untuk pengadaan pembelian alat dan pengolahan data.

\section{UCAPAN TERIMA KASIH}

Ucapan terima kasih kami sampaikan kepada Kementerian Riset dan Teknologi Pendidikan Tinggi yang telah membiayai penelitian ini melalui dana insentif riset flagship Insinas Tahun 2018. Ucapan terima kasih juga kami sampaikan kepada LAPAN, BIG, Bappeda daerah, Dinas PUPR, akademisi beberapa perguruan tinggi dan pihak-pihak lain yang mendukung.

\section{DAFTAR PUSTAKA}

A'yun, Q., Agung B., Udiana W. (2013). "Analisa Kelayakan Penggunaan Citra Satelit World View-2 untuk Updating Peta Skala 1:1000". Surabaya: ITS.

Ambodo, A. P. (2008). Aplikasi Penginderaan Jauh Dalam Mengidentifikasi Persebaran Mineral Bumi. Yogyakarta: Universitas Gajah Mada.

Amelia, N. R, Akhbar, I. Ariangsih. (2015). "Pembuatan Peta Penutupan Lahan Menggunakan Foto Udara yang Dibuat dengan Paramotor di Taman Nasional Lore Lindu (TNLL) (Studi Kasus Desa Pakuli Kecamatan Gumbasa Kabupaten Sigi)". Warta Rimba. Volume 3, Nomor 2, ISSN: 2406-8373, Desember 2015.

Auliya, P. Sasmito, B. Laila Nugraha, A. (2017). Efektivitas Penentuan Garis Pantai Menggunakan Citra Resolusi Tinggi dan Resolusi Menengah (Studi Kasus : Kabupaten Pacitan). Jurnal Geodesi. Vol.6, No.1, Hal. 267-276.

Harintaka. (2003). Penggunaan Persamaan Kolinier untuk Rektifikasi Citra Satelit SPOT secara Parsial. Teknik Geodesi UGM, Yogyakarta.

Kushardono, D. Dewanti, R. Ari Sambodo, K. Arief, R. Maryanto, A. Suhermanto. (2016). Kebutuhan Pengguna Data Penginderaan Jauh di Indonesia: Studi Awal Untuk Conceptual Design Review Satelit SAR Ekuatorial Indonesia Inarssat-1. ICOIRS 2016: The 2nd International Conference of Indonesian Society for Remote Sensing Remote Sensing for a Better Governance. Hal. 510-520.

Lilesand. T.M., W. Kiefer., Chipman, J.W. (2004). Remote Sensing and Image Interpretation (Fifth Edition). John Wiley \& Sons, Inc., New York.

Lillesand, Kiefer. (1994). "Penginderaan Jauh dan Interpretasi Citra". Gadjah Mada University Press, Yogyakarta.

Loveland, T.R. \& DeFries, R. (2004). Observing and Monitoring Land Use and Land Cover Change, In DeFries, R., Asner, G., \& Houghton, R., (eds.), Ecosystems and Land Use Change, Geophysical Monograph Series, Volume 153, American Geophysical Union, Washington, DC, 231-246.

Maryantika, N. (2009). Aplikasi Penginderaan Jauh Untuk Mendeteksi Kerapatan Vegetasi. 
Mather, P.M. (1987). Computer Processing of Remotly Sensed Data. Jhon Willey\& Sons, London.

Nurwauziyah, I. Muljo Sukojo, B. Hidayat, H. (2016). Analisis Ketelitian Geometric Citra Pleiades 1B untuk Pembuatan Peta Desa (Studi Kasus: Kelurahan Wonorejo, Surabaya). Jurnal Teknik ITS. Vol.5, No.2, A421-A426.

Projo, D. (1996). Pengolahan Citra Digital. Yogyakarta: Fakultas Geografi Universitas Gadjah Mada.

Rahayu, \& Candra, D. (2014). Koreksi Radiometrik Citra Landsat-8 Kanal Multispektral Menggunakan Top of Atmosphere (ToA) untuk Mendukung Klasifikasi Penutupan Lahan. In Seminar Nasional Penginderaan Jauh: Deteksi Parameter Geobiofisik dan Diseminasi Penginderaan Jauh (pp. 762-767)

Sudjana, Nana dan Ibrahim. (2001). Penelitian dan Penilaian Pendidikan. Bandung : Sinar Baru Algensindo
Susiati, H. (2010). Pola Sebaran Sedimen Tersuspensi Melalui Pendekatan Penginderaan Jauh.

Suwargana, Nana. (2013). Resolusi Spasial, Temporal Dan Spektral Pada Citra Satelit Landsat, Spot Dan Ikonos. Jurnal Ilmiah Widya. Vol.1, No.2, 167-174.

Taringan, M, S. (2008). Aplikasi Penginderaan Jauh Untuk Sebaran Dan Luas Hutan Mangrove Di Wilayah Pesisir.

Tufaila, M. Karim, J. Alam, S. (2012). Pemanfaatan Penginderaan Jauh Dan Sistem Informasi Geografis Untuk Pemetaan Bentuklahan Di DAS Moramo. Jurnal Agroteknos. Vol.2, No.1, Hal. 920.

Winardi, W. (2010). Studi Perubahan Tutupan Lahan Dengan Citra Landsat Menggunakan Geographic Resources Analyis Support System (Grass). 